\title{
Scientific Developments and the EPS-SG Scatterometer
}

\author{
Ad Stoffelen, Senior Member, IEEE, Signe Aaboe, Jean-Christophe Calvet, James Cotton, Giovanna De Chiara, \\ Julia Figa Saldaña, Alexis Aurélien Mouche, Marcos Portabella, Klaus Scipal, \\ and Wolfgang Wagner, Senior Member, IEEE
}

\begin{abstract}
The second-generation exploitation of meteorological satellite polar system (EPS-SG) C-band-wavelength scatterometer instrument (called SCA), planned for launch in 2022, has a direct heritage from the successful advanced scatterometer (ASCAT) flown on the current EPS satellites. In addition, SCA will represent three major innovations with respect to ASCAT, namely: 1) Cross polarization and horizontal copolarization; 2) a nominal spatial resolution of $25 \mathrm{~km}$; and 3) $20 \%$ greater spatial coverage than ASCAT. The associated expected science and application benefits that led the SCA design are discussed with respect to ocean, land, and sea ice applications for near-real time, climate monitoring, and research purposes. Moreover, an option to implement an ocean Doppler capability to retrieve the ocean motion vector is briefly discussed as well. In conclusion, the SCA instrument innovations are well set to provide timely benefits in all the main application areas of the scatterometer (winds, soil moisture, sea ice) and can be expected to contribute to new and more sophisticated meteorological, oceanographic, land, sea ice, and climate services in the forthcoming SCA era.
\end{abstract}

Index Terms-Eddy currents, radar signal processing, sea ice, soil measurements, storms, wind.

\section{INTRODUCTION}

$\mathbf{S}$ CATTEROMETERS are routinely used for monitoring winds and sea ice over the oceans and soil moisture over

Manuscript received January 9, 2017; revised March 26, 2017; accepted April 18, 2017. Date of current version May 24, 2017. (Corresponding author: Ad Stoffelen.)

A. Stoffelen is with the Royal Netherlands Meteorology Institute, De Bilt 3730, The Netherlands (e-mail: Ad.Stoffelen@knmi.nl).

S. Aaboe is with the Norwegian Meteorological Institute, Tromso 9006, Norway (e-mail: signeaa@met.no).

J.-C. Calvet is with Centre National de Recherches Météorologiques, Toulouse 31057, France (e-mail: jean-christophe.calvet@meteo.fr).

J. Cotton is with Met Office, Exeter EX1 3PB, U.K. (e-mail: james.cotton@ metoffice.gov.uk).

G. De Chiara is with European Centre for Medium-Range Weather Forecasts, Reading RG2 9AX, U.K. (e-mail: giovanna.dechiara@ecmwf.int).

J. F. Saldaña is with Europäische Organisation für meteorologische Satelliten, Darmstadt 64295, Germany (e-mail: julia.figa@eumetsat.int).

A. A. Mouche is with the Laboratoire d'Océanographie Physique et Spatiale, Institut Français de Recherche pour l'Exploitation de la Mer, Plouzane 29280, France (e-mail: alexis.mouche@ifremer.fr).

M. Portabella is with the Institut de Ciències del Mar-Spanish National Research Council, Barcelona 08003, Spain (e-mail: portabella@cmima.csic.es).

K. Scipal is with European Space Agency, Noordwijk 2200, The Netherlands (e-mail: Klaus.Scipal@esa.int).

W. Wagner is with the Vienna University of Technology, Wien 1040, Austria (e-mail: wolfgang.wagner@geo.tuwien.ac.at).

Color versions of one or more of the figures in this paper are available online at http://ieeexplore.ieee.org.

Digital Object Identifier 10.1109/JSTARS.2017.2696424

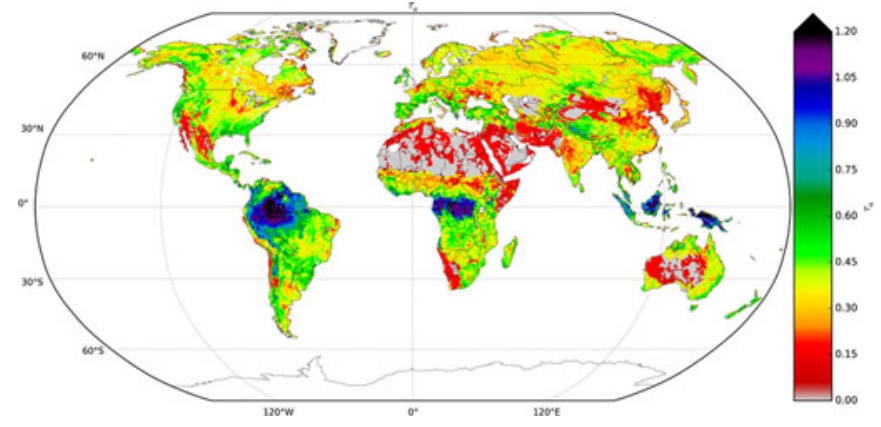

Fig. 1. Global map of average ASCAT vegetation optical depth over 20072011, cf. [16].

land, supporting an increasing number of geoscientific applications. For example, ocean surface wind vectors [1], [2] are an important input to global [3] and regional numerical weather prediction (NWP) [4]. They are also used as a forcing agent in ocean models [5] to improve the modeling of waves [6], storm surges [7], and ocean currents [8]. Moreover, observations supporting the coupled atmosphere-ocean system are fundamental for seasonal and longer range forecasting, e.g., allowing an adequate representation of phenomena, such as El Niño and the atmospheric and ocean circulation, in general [9]. The near-real time demand for ocean wind observations is further emphasized by the increased need for accurate storm and hurricane forecasting in nowcasting applications [10]. More recently, economic interest in coastal wind forecasts and climatologies is increasing, due to developments in, e.g., off-shore energy applications [11] and increasing sea transports.

Over land, scatterometer measurements are used to monitor surface soil moisture (SSM) [12] and freeze/thaw status [13] to support NWP, hydrology, agriculture, and other related applications areas [14]. SSM is of major importance in global and regional earth system models, because of the direct impact on many physical, chemical, and biological processes and feedback loops taking place at the land surface and within the atmosphere. Moreover, scatterometer-derived SSM estimates have proven their capability to monitor extreme hydrological events like droughts and floods, and to serve as an entirely new data source for estimating rainfall amounts over land [14]. Also, recent research has shown that $\mathrm{C}$-band scatterometers have the ability to observe vegetation parameters [15], [16], as illustrated in Fig. 1. 


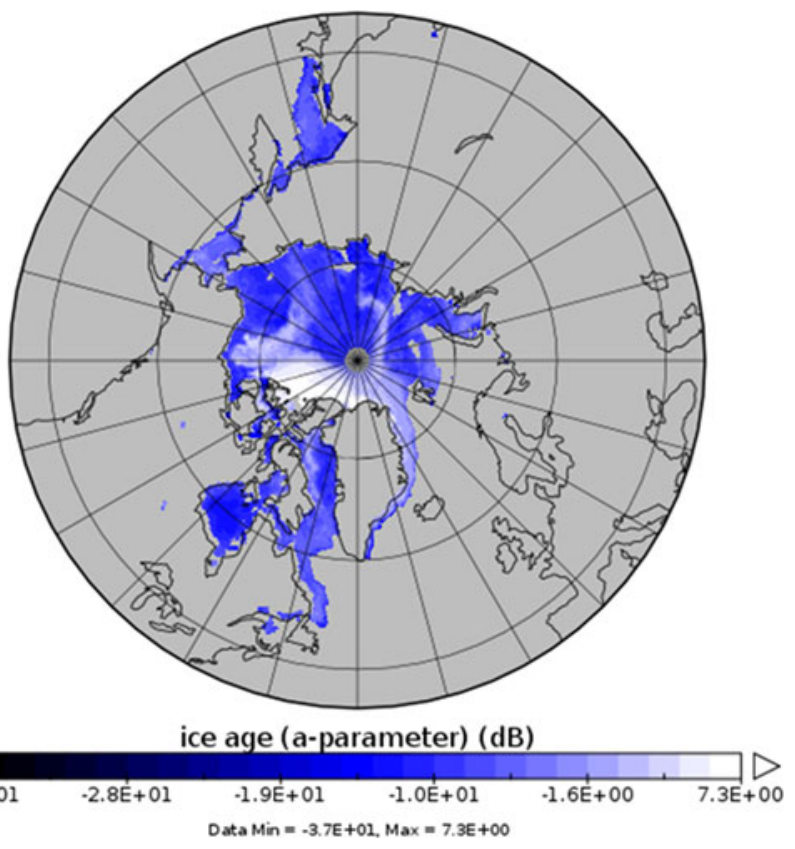

Fig. 2. Arctic map of the ASCAT sea ice extent and ice age parameter a.

With respect to the cryosphere, scatterometer data are used in the retrieval of several sea ice parameters, such as sea ice coverage, type, and drift [17], as illustrated in Fig. 2. Sea ice products are used for economic activities, mainly in the marginal ice zone. Sea ice monitoring is very relevant in climate applications as the role of sea ice dynamics in the earth system is not very well understood.

Climate data records (CDR) of proven homogeneity are fundamental to study climate change and variability [18], [19], thus focusing on the consistency, stability, and intercalibration of the different sensor records. The combination of existing C-band and $\mathrm{Ku}$-band scatterometer data archives into a single CDR shall provide an invaluable continuous record of observed ocean surface vector winds, soil moisture, and sea ice extents covering an era from 1991 to the present date. The global climate observing system (GCOS) program defines guidelines for the provision of satellite-based essential climate variables, prescribing a stability requirement of $0.1 \mathrm{~m} / \mathrm{s}$ per decade for the provision of ocean surface wind speeds [20]. This translates into a relative beam stability of $0.1 \mathrm{~dB}$ for C-band scatterometers which appears well achievable. For soil moisture, the current GCOS stability requirement is $0.01 \mathrm{~m}^{3} \mathrm{~m}^{-3} \mathrm{yr}^{-1}$, which also translates into a relative beam stability of about $0.1 \mathrm{~dB}$ over grassland and agricultural areas where the range of backscatter from dry to wet conditions is $4 \mathrm{~dB}$ or larger. While the homogenization of $\mathrm{C}$-band and $\mathrm{Ku}$-band scatterometer winds remains a challenge, mainly because of their different radar physics and processing [21], [22], the homogenization of the C-band record formed by the advanced scatterometer (ASCAT) data collected on the Metop-A platform [23] and the active microwave instrument (AMI) data collected on the European Remote Sensing ERS-1 and ERS-2 platforms [24] is now obtainable [25].

Metop-SG is the space segment of The European Organization for the exploitation of meteorological satellites (EUMETSAT) polar system second generation (EPS-SG). The satellites
TABLE I

AEG PRIORITIZATION, INCLUDING FEASIBILITY, OF THE SCA MISSION PARAMETERS

\begin{tabular}{lccc}
\hline \hline Application & Ocean Vector Winds & Soil oisture & Sea Ice \\
\hline Global NWP & 1 & 2 & 2 \\
Regional NWP & 1 & 2 & 2 \\
Nowcasting & 1 & & \\
Oceanography & 1 & 1 & 1 \\
Hydrology & 1 & 2 & 1 \\
Climate & & & \\
\hline \hline
\end{tabular}

Priorities range from 1 (prime) to 4 (low) [26].

will carry a C-band-wavelength scatterometer instrument (here called SCA) that has a direct heritage from the ASCAT and AMI instruments, following their successful application in the atmospheric, sea, land, and cryospheric domains, as mentioned above. The EPS-SG and SCA user requirements were assessed by diverse Application Expert Groups (AEG) before its design phase [26]. An overview of this assessment is briefly recollected in Table I for the application areas mandated to EUMETSAT. Since nearly a decade has passed since the assessment in 2008, a general revaluation by the AEG appears justified taking into account the latest scientific evidence [27].

An EPS-SG scatterometer mission is well supported in all the different application areas included in the EUMETSAT mandate. The overall high priorities and feasibility warrant the continuation and extension of the EUMETSAT scatterometer mission.

As a baseline, the expected performance of SCA is that of its predecessor ASCAT [28,29]. However, the SCA design has three major innovations with respect to ASCAT, in particular [30].

1) Cross polarization and horizontal copolarization.

2) Spatial resolution of $25 \mathrm{~km}$.

3) $20 \%$ greater spatial coverage than ASCAT.

Moreover, an option to implement an ocean Doppler capability to retrieve the ocean motion vector has been investigated [31]. In this paper, the benefits of these innovations on the applications are discussed in respective order and in the context of the anticipated due progress. In addition to SCA, the MetopSG platform B will carry a MicroWave imager, called MWI. Synergies between SCA and MWI will be further presented.

\section{CROSS POLARIZATION AND HH COPOLARIZATION}

The alternate cross polarization (here denoted VH for simplicity) on the mid beams will improve the extreme wind speed range and initial research has provided first empirical and theoretical insights on the $\mathrm{VH}$ sensitivity at extreme winds (e.g., [32]-[34]). Further scientific elaboration of the VH signal behavior for ocean [35], soil, and cryospheric applications will be necessary, as well as elaboration of the geophysical retrieval methodologies to include the VH sensitivity.

$\mathrm{VH}$ polarization measurements are very important for weather forecasting because they have the potential of extending the useful range of SCA wind speeds to $40 \mathrm{~m} / \mathrm{s}$, or higher (see Fig. 3). Like for many others, it is a key part of the European Centre for Medium-Range Weather Forecasts (ECMWF) strategy to 


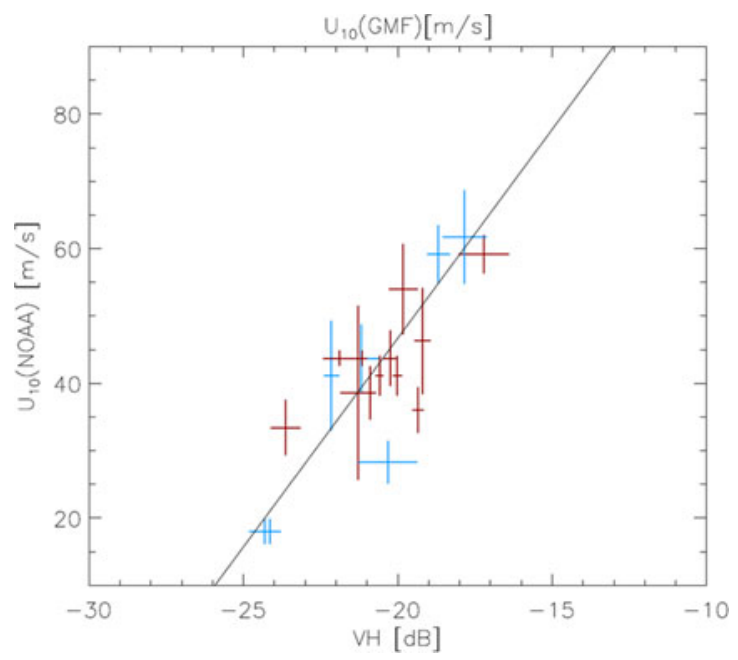

Fig. 3. Extreme 1-min sustained 10-m wind speed gusts, derived from RadarSat VH-polarization and compared to air-based wind data from NOAA, cf. [32].

improve forecasts of severe weather [34] and to track severe tropical and extra-tropical storms in nowcasting, an accurate analysis of strong winds is important. Whilse such strong winds are relatively rare, their impact on economy and society is enormous and, due to increasing population and infrastructure, increasing over time.

In addition to extending the wind range, $\mathrm{VH}$ is expected to improve vegetation determination in conjunction with soil moisture retrieval [36]. For example, Aquarius VH-polarized and VV-polarized backscatter observations at L-band were compared to existing vegetation datasets [37]. The cross-/copol ratio captures vegetation dynamics over most vegetation zones well. Interestingly, differences in dynamics are observed between vegetation products from active and passive microwave measurements. VH is also expected to lead an improved characterization of volume scattering effects by the vegetation, (dry) snow, and soil. This demonstrates that valuable information can be gained from vegetation products of scatterometers at $\mathrm{VV}$, $\mathrm{HH}$, and $\mathrm{VH}$ [37].

VH will help to better distinguish open water surfaces from surrounding land surface areas. Additionally, the higher sensitivity of VH to volume scattering in snow, and sea ice is expected to further progress the monitoring of freeze/thaw processes and detection of open water surfaces versus sea ice. Experiences with cross-polarization C-band channels used for detecting sea ice are more developed with data from synthetic aperture radar (SAR), which also measures the radar backscatter. Modern SAR systems, such as RADARSAT-2 and Sentinel-1, use a C-band radar and provide data at different preselected polarizations. In the ice charting community, the $\mathrm{HH}$ - and HV-polarizations are often used for sea ice monitoring. The contrasts between ice and water are higher in $\mathrm{HH}$-polarized images than in VV images [38]. However, over open water and high winds, the copolarized backscatter from both $\mathrm{HH}$ and $\mathrm{VV}$ is similar to that of sea ice, such that the separation of ice and water may be difficult [39]. The cross-polarized ( $\mathrm{HV}$ or $\mathrm{VH}$ ) backscatter is much lower, and, therefore, better suited for ice-water discrimination in regions of strong winds [40]. The additional polarization channels on
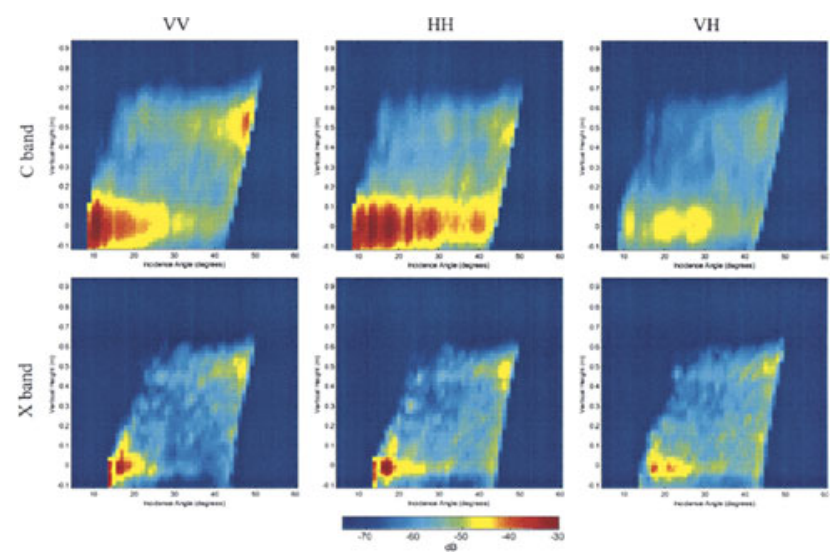

Fig. 4. Radar cross-sectional images of a green and 58-cm-tall wheat canopy acquired by an experimental profiling radar at $\mathrm{C}$ - and $\mathrm{X}$-bands at $\mathrm{VV}, \mathrm{HH}$, and $\mathrm{VH}$ polarizations. Horizontally, the incidence angle ranges from $5^{\circ}$ to $60^{\circ}$ and vertically height from -11 to $93 \mathrm{~cm}$. Soil returns appear most dominant in Cband, whereas $\mathrm{HH}$ shows the strongest soil signal due to the reduced extinction of horizontally oriented waves by the predominantly vertically oriented vegetated elements from [49].

SCA are, therefore, expected to provide very useful contribution to sea ice detection.

Over water surfaces, VH signals are about $15 \mathrm{~dB}$ lower than VV. This may possibly pose measurement limitations, due to the $1^{\circ}-3^{\circ}$ Faraday polarization rotation in the ionosphere [41], causing an emitted pure vertical polarization (V) signal to become partially horizontal polarization $(\mathrm{H})$ and vice versa. This implies that emitted vertical polarization results in $\mathrm{HH}$ scattering off the ocean surface, which in turn contaminates the $\mathrm{VH}$ measurement, since it implies the measurement of Zadelhoff et al. [32] used combined satellite VV and VH measurements in hurricanes and found a little angular dependence of the $\mathrm{VH}$ measurements, implying a little contamination by $\mathrm{HH}$ as this has strong angular dependence. It should be noted, however, that those measurements (cf. Fig. 3) were taken during a period of solar inactivity, and, thus, reduced Faraday rotation. A main investigation for SCA will remain in the characterization of this effect. In particular, spatial and geographical variations will be of interest, as well as the capability to forecast the Faraday rotation.

At the extreme winds, the difference between $\mathrm{VV}$ and $\mathrm{VH}$ is much reduced and Faraday rotation effects on $\mathrm{VH}$ are, thus, limited; hence, this is not compromising the main SCA mission of measuring extreme winds where VV- and $\mathrm{HH}$-polarization measurements are saturated.

The required SCA VH capability implies $\mathrm{HH}$ measurements become possible too. Over the ocean $\mathrm{HH}$ sensitivity is lower than VV sensitivity, and, thus, replacing VV with $\mathrm{HH}$ is generally not expected beneficial. However, over land surfaces, the new copolarization $(\mathrm{HH})$ channel will in particular help to improve the quality of the soil moisture retrievals due to the reduced sensitivity of $\mathrm{HH}$ (compared to VV) to vertically oriented vegetation elements over grassland and agricultural areas (e.g., see Fig. 4).

Taking note of the scientific advances in our understanding of the interaction of microwaves with the land surface, one can confidently predict that SCA will not only allow for improved 
soil moisture and freeze/thaw retrievals, but also for delivering several novel data products, including but not limited to vegetation water stress [42]-[44], vegetation optical depth [45], and aerodynamic roughness [46]. Over land, renewed efforts in building advanced backscatter models [47] and new experimental approaches (e.g., [48]) are needed to better disentangle the backscatter contributions from different parts of the vegetation canopy and the soil profile. This will improve not only the quality of the soil moisture retrievals, but will at the same time allow the development of new land data products for SCA. Moreover, for semiarid regions, there is a strong need for further research to understand the co- and cross-polarization scattering contributions from the stratified upper soil layers and their dependence on environmental conditions.

\section{SPATIAL RESOLUTION}

Many users cry out for increased spatial resolution products, but producers need to strike a complex balance between technical feasibility, spatial coverage, spatial resolution, noise, and achievable information content.

Over the ocean, the SCA breakthrough horizontal resolution of $25 \mathrm{~km}$ will give a better handle on physical processes, such as turbulent flows, convective systems, tropical cyclones, polar lows, coastal phenomena, air-sea interaction, eddy-scale oceanography, and tropical circulation. In particular, improvements in the coastal region brought by increased resolution will be beneficial for many weather and climate applications.

Over land, the higher resolution of SCA will result in better resolved soil moisture and temporal soil characterization. For soil moisture, many geophysical applications such as hydrology and agriculture request high spatial resolution and there is no satellite mission proposed that fully meets all requirements. While instruments like SMOS and SMAP operate at a longer wavelength (L-band) to enhance their sensitivity to soil moisture under vegetation, as compared to C-band [50], [51], their spatial resolution remains rather coarse, leading to adverse error properties [52]. Also Sentinel-1, which like ASCAT provides C-band $\mathrm{VV}+\mathrm{VH}$ backscatter observations, albeit at a much increased spatial resolution $(20 \mathrm{~m})$, is very promising [53]. However, its temporal sampling rate varies from biweekly in well sampled areas, such as Europe to bimonthly for most of the global land surface.

Over sea ice, the higher SCA resolution will provide improved sea ice characterization and drift determination. Highresolution twice-daily and improved-sensitivity measurements will aid in the development and understanding of, e.g., dynamical sea ice models, particularly in the marginal sea ice zones. If scatterometer observations are indeed available at much higher spatial resolution, they can add significant new information. Recently, much research has gone into the spatial processing of ASCAT data over sea [54], [55], land [56], and sea ice [57], [17], following research on ASCAT near-coastal winds [58], where improvements due to improved spatial filtering are found in all domains with respect to the nominal products. Moreover, taking into account the shape and orientation of the basic spatial response functions (SRF) of ASCAT, and after a careful matching of the cumulative SRFs (CSRFs) of its three beams, a $5.6-\mathrm{km}$ wind product with $<20-\mathrm{km}$ spatial resolution has been constructed. A key asset for such resolution enhancement is the radiometric noise (Kp) [55]. Together with the SRFs, it determines the maximum resolution achievable at an acceptable noise level. For land and sea ice applications, further resolution enhancement is possible in principle for ASCAT by combining the SRFs of the three beams for different azimuths and times, as these targets are less anisotropic and more stable [17], [59]. Yet, ambiguities will remain, particularly in case of mixed pixels (e.g., mixture of wet snow, standing water, and thawed ground). Therefore, approaches like the one proposed by Zwieback et al. [60] who combined the backscatter data with auxiliary dataset (like air temperature) for freeze/thaw detection should be further investigated.

As compared to ASCAT, SCA will have a reduced size of the SRF by a factor of 2 , improved radiometric noise, and no onboard averaging, all of which will help in achieving increased resolution over sea, land, and ice to the benefit of the SCA product users.

\section{Coverage}

Coverage matters due to the fast evolution of small-scale atmospheric processes and a scatterometer constellation is needed for dense time coverage over land and oceans. Soil moisture evolution and the extraction of precipitation estimates from it, similarly critically depends on complete coverage [14]. Frustratingly, frequently key weather events are missed due to incomplete coverage by ASCAT. The wider swath will improve the ASCAT coverage (by 20\%) and makes SCA more comparable to existing $\mathrm{Ku}$-band scatterometers in this respect. Another aspect is to ascertain whether we can gain more impact in NWP if there is less overlap between the successive scatterometer swaths, i.e., increasing the total spatial coverage.

With more agencies now building and operating scatterometers (e.g., the Indian ScatSat, the future HY and FY Chinese satellites, and the Chinese-French CFOSAT scatterometer), a multiagency constellation is being progressively built to better address spatiotemporal coverage. EPS Metop-SG will have a consolidated midmorning orbit position in this Constellation [62].

Given the launch schedule of Metop/Metop-SG satellites and the typical lifetime of scatterometers, a tandem SCA configuration may be offered for the benefit of all scatterometer applications. This may provide almost complete coverage in a single pass of the tandem, when the tandem is optimally separated by a quarter orbit length, as illustrated in Fig. 5. For ASCAT, the 50-min separation for Metop-A and Metop-B has not been optimal since this leaves significant coverage gaps in the tropics and the overlapping data are fairly close in time [63]. Depending on the end of life scenario for Metop-A, there may be an opportunity to compare the impact of two ASCAT's at 50-min separation (e.g., ASCAT-B/A) with two ASCAT's at 30-/70minute separation (e.g., ASCAT-B/C). Having three Metop's in orbit at the same time is the only way to get a direct comparison through conducting observing system experiments within NWP. 


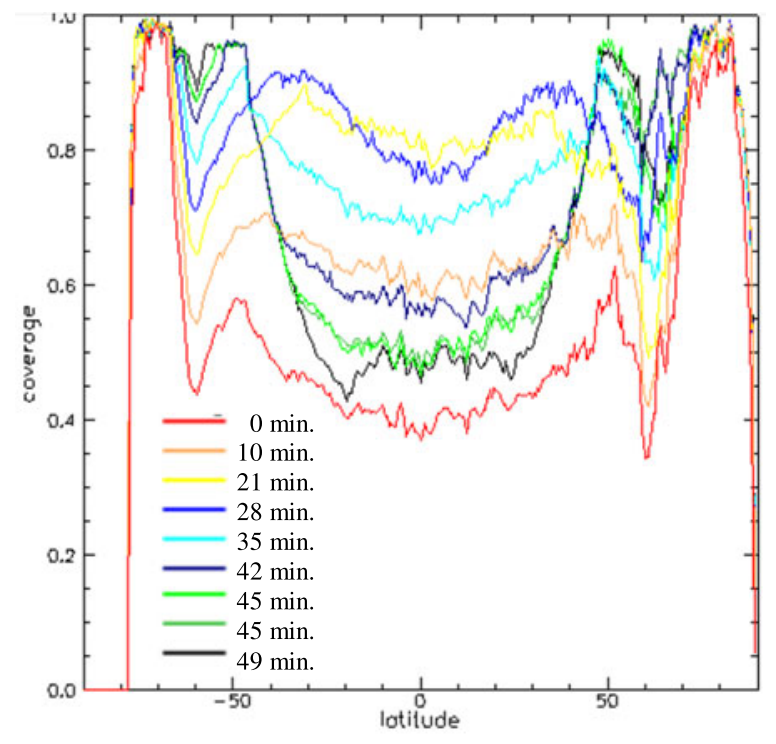

Fig. 5. Tandem coverage over sea for different ASCAT-A and ASCAT-B orbit phase separations [61]. SCA's tandem coverage will be larger.

\section{Potential DopPler CAPABility}

A SCA Doppler capability would offer several opportunities for improving scatterometer products. Recently, over ocean, C-band Doppler shift measurements as obtained with SAR revealed that the geophysical contribution to the Doppler shift includes ocean surface currents, sea state, and local windinduced ocean surface velocity contributions. Chapron et al. [64] (qualitatively) and then Rouault et al. [65] (quantitatively) show how the ocean current contribution to the Doppler shift can be measured after a careful correction of the sea-state contribution, based on ancillary information on the wind vector, which is the prime SCA mission. Furthermore, on a global scale and at $10-\mathrm{km}$ resolution, wind can be used as a proxy for ocean motion [64]. This leads Mouche et al. [66] to propose a first forward geophysical model function (GMF) that relates wind speed and direction (with respect to antenna look direction) as a function of incidence angle $\left(17^{\circ}-42^{\circ}\right)$ for both $\mathrm{VV}$ and $\mathrm{HH}$ to a geophysical Doppler shift. They show for SAR how Doppler helps to constrain the wind retrieval (see Fig. 6). In particular, it helps the wind direction retrieval in complex situations, such as atmospheric fronts and low pressure systems. Moreover, for extreme winds, the Doppler wind direction sensitivity could be very complementary to the cross-polarization radar cross section, since cross polarization has no sensitivity to wind direction [59]. Therefore, Doppler information may enhance scatterometer wind retrieval and ambiguity removal, and improved wind vector information which in turn enhance ocean surface current determination.

Scatterometer winds are measured relative to the moving ocean surface, which wind vector frame is often most relevant for operations at sea. However, buoy and NWP model winds are provided with reference to a fixed earth reference. Comparison of scatterometer and Buoy and NWP datasets, therefore, require that ocean currents are known [68]. Direct eddy-scale current measurements would greatly improve ocean modeling, particularly in the tropics. After a first simulation study, Fois et al. [31]

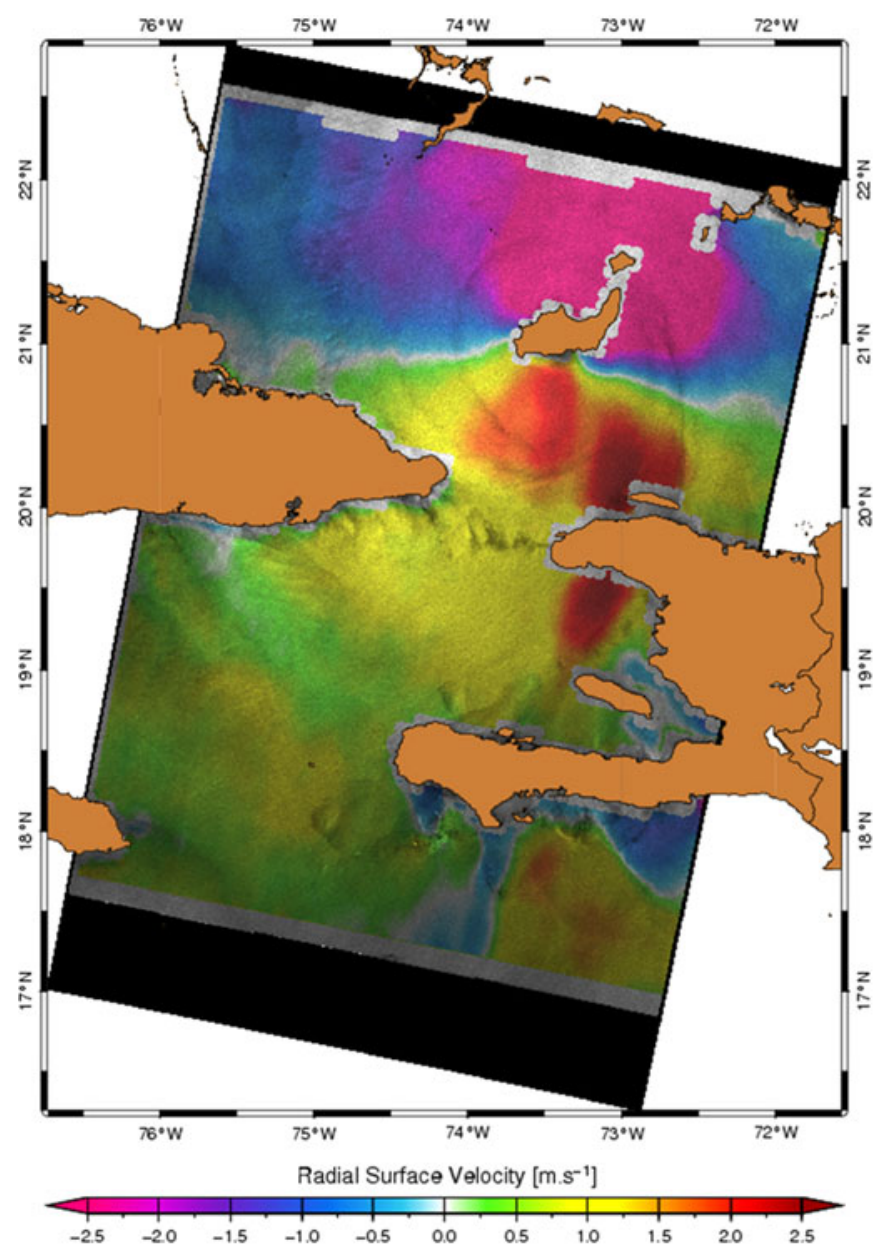

Fig. 6. Radial surface velocity as measured in hurricane Ike on 8 September, 2008 14:53 UTC by ESA ENVISAT Doppler capability. Ocean motion in excess of $2 \mathrm{~m} / \mathrm{s}$ is seen toward (red) and away (purple) from the SAR, which provides essential wind direction information.

showed the potential of SCA to determine ocean currents. This potential is currently further elaborated taking the specific SCA design into consideration and, in particular, investigating if the required performance can be achieved in practice.

\section{SCIENTIFIC PROSPECTS FOR SCA APPLICATIONS}

Following the above-noted enhancements offered by the SCA instrument, due progress in scatterometer applications is elaborated below. Such anticipated progress is associated with the SCA innovations, and, therefore, necessary for maximal operational SCA benefit in the application areas.

\section{A. Using SCA Wind Variability}

Stoffelen [69], and Portabella and Stoffelen [70] found that the normalized inversion residual, called MLE, is well capable of removing cases with extreme wind variability (at fronts or centers of lows), or with other geophysical variables affecting the radar backscatter. Recently, further progress has been made in the quality assessment of ASCAT winds near rain [71]-[73] and it is confirmed that the MLE mainly represents enhanced wind variability. Generally, the MLE is positive and large when 


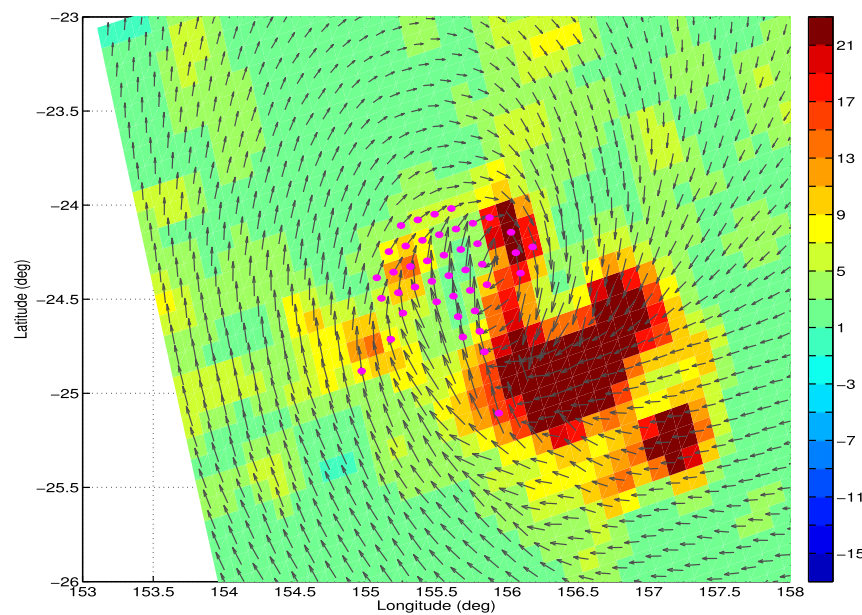

Fig. 7. ASCAT innovations in wind inversion residual sign (MLE; color) as a measure of local wind variability and in wind direction ambiguity removal (at the pink dots) for a dynamical mesoscale system in the southern Indian ocean. Green MLE colors correspond to flow with low sub-WVC wind variability, while red colors indicate very large local wind variability, often due to wind downbursts in moist convective precipitation [67].

there is substantial wind variability within the cell, see e.g., Fig. 7. Negative MLEs occur for stable flows.

Enhanced positive MLE corresponds to wind shifts due to convective downbursts, fronts, and other dynamical phenomena. Such phenomena may span several wind vector cells (WVC) and a local spatial analysis of MLE and singularity exponents (SE) provides an effective quality control (QC) [72]. SEs are obtained from singularity analysis, a spatial image processing technique, effective in detecting local decorrelation in a field. Also, such measures of wind variability are much desired in scatterometer applications, such as nowcasting and NWP.

\section{B. Improving Land Applications}

As mentioned above, scatterometers have a high potential for monitoring vegetation dynamics due to the fast revisit time and the VH-cross-polarization measurement at high radiometric accuracy. This allows the depiction of seasonal and intraannual changes in the incidence angle behavior of the backscatter measurement with high accuracy. This may be highly valuable information for monitoring of vegetation dynamics by the vegetation optical depth (see Fig. 1), which is closely related to vegetation water content and height [45]. By averaging backscatter measurements over longer time intervals, information about vegetation characteristics can also be estimated from averaged backscatter measurements [44] or by comparing diurnal differences in backscatter [22]. Such information will improve the retrieval of soil moisture but can also be exploited as a selfstanding product.

Additional improvements in the soil moisture product are expected from a better characterization of scattering in arid and semiarid environments. Backscatter from vegetated and bare soil is, in general, positively correlated with soil moisture. However, over some arid and semiarid environments, an inverse relationship is observed (see Fig. 8). Wagner et al. [12] hypothesized that this phenomenon is caused by the high penetration of

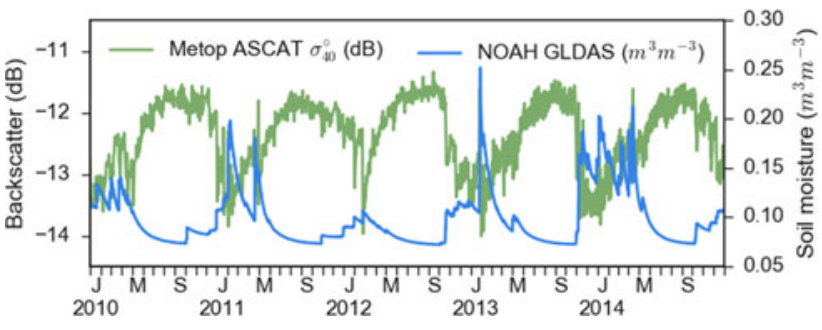

Fig. 8. ASCAT backscatter time series (normalized to $40^{\circ}$ incidence angle) over a desert area in Saudia Arabia $\left(30.72^{\circ} \mathrm{N}, 40.85^{\circ} \mathrm{E}\right)$. The backscatter time series shows an inverse behavior as the soil moisture time series modeled by NOAH GLDAS [76]. The figure was kindly provided by S. Hahn, TU Wien.

microwaves into dry soil and the presence of strong subsurface scatterers in line with recent experiments [74], [75]. Potentially, extension of this research may lead to a better understanding of land degradation and desertification processes.

\section{Sea Ice Application Evolution}

The microwave backscatter over sea ice is dependent on the ice surface roughness and on the degree of volume scattering from brine pockets within the ice to which $\mathrm{VH}$ is sensitive.

Current experience has been gained with classification of sea ice from the Sentinel-1 satellites. As an input to manual ice charting the Sentinels are great both in terms of quality and coverage. However, when it comes to automatic ice classification, there are considerable challenges, mainly due to processing artifacts in the SAR image, such as scalloping and gain shift, particularly at low winds over water. The largest differences between SAR and scatterometer are the higher resolution of SAR, the multiple viewing directions of a scatterometer, and the superior calibration stability of a scatterometer. Because of the SCA calibration stability and accuracy, we expect to see an improved objective classification based on the SCA VH, albeit at coarser resolution. Therefore, the prospect of combining the measurement from Sentinel-1 and SCA, which are otherwise very similar, is indeed very promising. In the context of the Copernicus Marine Environment Monitoring Service, work is ongoing to combine Sentinel-1 data with passive microwave data. SCA and MWI will simultaneously provide the synoptic full polarimetric capability at both poles. The potential areas of usage range from high-resolution automatic ice charting for tactical navigation to large-scale sea ice analysis to support, e.g., climate models.

\section{Backscatter Assimilation Over Land}

Today, a number of users (e.g., ECMWF, Météo-France, UKMO) assimilate the ASCAT L2 SSM product. Over vegetated areas, this product is affected by the vegetation structure and water content and this may impact the seasonal and interannual variability of the L2 SSM. As a result, a complex seasonal rescaling has to be performed before the integration of this product into land surface models (LSMs). Some LSMs have a representation of plant growth (above-ground biomass, vegetation type, LAI). Potentially, such models could provide the missing information about vegetation. At the same time, the backscatter signal could help analyzing vegetation biomass 
together with soil moisture. An interesting development would be to develop (simple, e.g., quasi-linear) observation operators in LSMs giving the LSM the capability to simulate backscatter. This would, in the future, allow the assimilation of multiangle and/or resolution-enhanced backscatter products over land.

A driver for improvements to the global observing system for LSM is an increasing need for information on the $10-\mathrm{km}$ scale, as global and regional NWP models move to ever higher horizontal resolutions. In the next few years, global weather forecasting will explore LSM resolutions below $10 \mathrm{~km}$, e.g., ECMWF anticipates a resolution of $5 \mathrm{~km}$ (T3999) around 2020. With sub 10-km grid lengths, we would expect LSM to resolve much smaller scales, e.g., coastal effects, and other sharp LSM gradients, probably associated with the presence of extreme weather conditions.

\section{E. Wind Assimilation}

For wind data assimilation, we may identify the deterministic scale, which is the scale supported by observations in both space and time to deterministically initialize the smallest (short-lived and small-amplitude) evolving scales in weather models [77], [78]. These scales will remain larger than $100 \mathrm{~km}$ over sea due to persisting lack of temporal wind observation coverage. In addition, the effective dynamical model resolution may be defined, which is 5-10 times the grid length [4] and smaller than the mentioned deterministic scale. The ongoing challenge will be to maximize the benefit from higher resolution observations to help support small-scale structures, while the temporal coverage over sea remains limited [62]. This means that model scales smaller than the deterministic scale, essentially weather model noise, needs to be accounted for the first time in data assimilation. For regional NWP, very-high horizontal resolution models with grid lengths of $300 \mathrm{~m}$ or less are anticipated at the Met Office and elsewhere. For fine-scale model grid lengths, it will be important to take into account the scatterometer footprint to reduce the representativeness errors and take account of the deterministic scales [4]. With increased supercomputer resources, mesoscale model improvements can be expected from the use of rapidly updating 4-D-Var assimilation schemes, resolving the temporal and spatial scales of convection. Further research will be needed to develop more realistic situation-dependent model and observation error schemes (based, for example, on the wind variability within the resolution cell [67]) that can improve the balance in the weight given to observations and background and provide the optimal spatial filtering in the analysis.

NWP data assimilation is based on a best linear unbiased estimate (BLUE), and generally bias correction schemes are used to remove observation minus model biases. Fig. 9 shows typical NWP model biases against scatterometers.

We note that the largest differences between scatterometer and ECMWF model winds appear in regions near the ITCZ, regions with ocean currents and near land masses or sea ice. These areas correspond to areas with large atmospheric dynamics and extensive moist convection. Besides substantial speed biases, substantial systematic wind direction biases also exist [79]. NWP biases occur in all NWP models and are due to fast

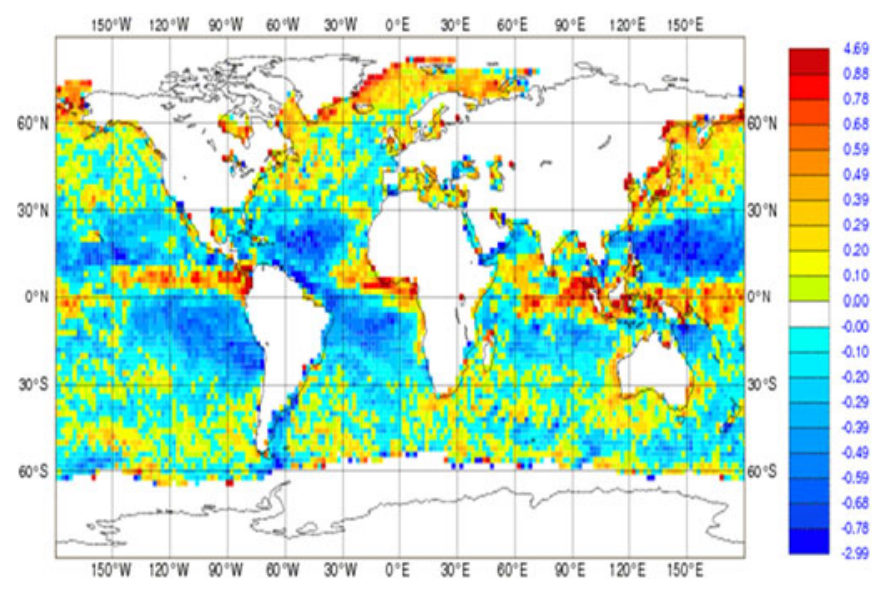

Fig. 9. Accumulated statistics for 10-m equivalent-neutral mean wind speed differences in $\mathrm{m} \cdot \mathrm{s}^{-1}$ between ASCAT-A and ECMWF first guess for the period from 21:00 UTC on 31 October, 2015 until 9 UTC on 5 December, 2015 in boxes of $2^{\circ} \times 2^{\circ}$

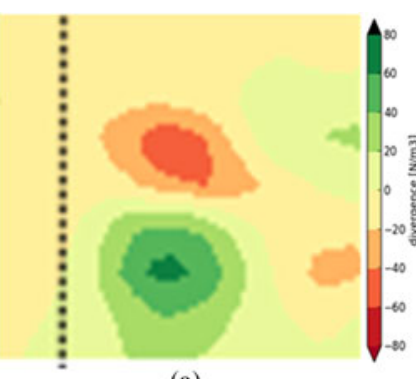

(a)

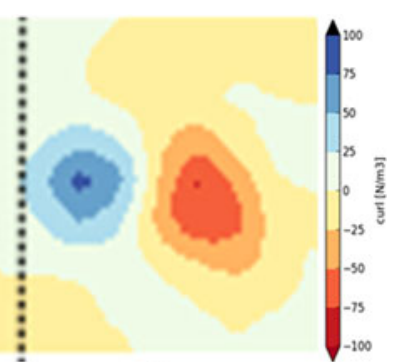

(b)
Fig. 10. Characteristic depiction of a deep moist convective cell in the tropics by ASCAT-A wind derivatives at $12.5-\mathrm{km}$ sampling of divergence (left) and curl (right) over a $250 \mathrm{~km} \times 250 \mathrm{~km}$ area on 4 February 2014 near $0 \mathrm{E}$ (dotted line), $3 \mathrm{~N}$. The cell convergence, shear, and wind downburst divergence are clearly visible, depicting the intense air-sea interaction of tropical moist convection.

or mesoscale processes resolved by the scatterometer, but not by models, such as (moist) convection [72], atmospheric turbulence [80], gravity waves, and systematic errors in boundary layer parameterizations or the lack of ocean currents. These biases tend to persist over time (not shown). The occurrence of these spatial biases is, however, ignored in data assimilation and their existence prevents the correct assimilation of observed dynamical weather features, following BLUE, and it, thus, may be worthwhile to develop local bias reduction schemes for scatterometers.

\section{F. Convection}

The next grand challenge in NWP and climate prediction is to better understand the role of clouds in atmospheric circulation. In particular, cloud parameterizations are difficult to verify and new observations, e.g., that depict convection, are welcome. Convection is also associated with air downbursts that substantially affect air-sea interaction, another not wellunderstood aspect of climate change. Fig. 10 shows an example of scatterometer-derived curl and divergence near a moist convective cell over ocean. The wind downburst divergence is clearly visible and coincides exactly with the precipitation cell 
as observed by a geostationary satellite (not shown). Moist convection is widespread in the tropics and results in intense air-sea interaction. Further research in wind derivatives of tandem scatterometers, such as ASCAT-A and ASCAT-B in association with geostationary time loops of precipitation may shed further light on the dynamical aspects of moist convection and the related physical parameterizations [81].

\section{G. Coupled Atmosphere-Ocean-Land Assimilation}

NWP centers are currently devoting a significant effort to increase the level of coupling between different components of the earth system (Atmosphere, Ocean, and Land) in both global and regional models. The ambition is to move as close as possible to fully coupled models and data assimilation systems. The first weakly coupled data assimilation systems are already under development [82]-[84]. While they rely on coupled models, a part of the data assimilation process is still performed separately for the individual components of the earth system. Developing stronger coupling within the data assimilation process is the next challenge. These future systems will allow more effective exploitation of near-surface observations, such as scatterometer winds, soil moisture, and sea ice, that have an impact on both atmosphere and surface.

\section{H. Extreme Wind Speeds}

With SCA, we expect accurate winds over a larger dynamical range compared to ASCAT [32], [85]. This opens the opportunity for NWP centers to exploit the data up to higher wind speed thresholds (current upper thresholds for ASCAT are $25 \mathrm{~m} / \mathrm{s}$ at the Met Office [63] and $35 \mathrm{~m} / \mathrm{s}$ at ECMWF [3]). How high can the thresholds go? To a large extent this will depend on how good the model winds are under extreme conditions. If the model winds are not accurate, it will be difficult to assimilate the information. This is because if the difference between the model and the scatterometer is too large then the observation will likely be rejected. Moreover, an aliasing problem often occurs in cases with fast moving storms or tropical cyclones, when the storm center is misplaced in the model background. Therefore, an active area of research remains, on the one hand, to improve model parameterizations at extreme winds and, on the other hand, the QC and weights applied in variational assimilation so that observations with larger departures can be given a higher or nonzero weight in forming the analysis [86].

\section{DISCUSSION}

For SCA, geophysical products on wind, soil moisture, vegetation, precipitation and sea ice, and snow quantities will be developed and in the long term added to intercalibrated thematic CDRs. Future developments include improved spatial and temporal resolution over land and sea, and, in particular, in coastal regions.

Concerning increased spatial resolution and near-coastal processing, the exact knowledge of the SRF is important [87], [88], as well as the availability of full-resolution (nonaccumulated) samples. It is essential that the fore, mid, and aft beams view the same area, i.e., view the same wind vector or land cell. If the CSRF is different for the fore mid and aft beams, then the consistency of the backscatter values with the GMF will be degraded. Matching CSRFs are challenging for the smaller footprints, due to the different basic sampling of the three beams and will continue for SCA. For soil moisture and sea ice, a different opportunity arises, as the signal levels are high and the response is to a first-approximation azimuthally isotropic over the majority of land surface areas. This offers the possibility of resolution enhancement when the three beams do not exactly overlap over land and sea ice areas [59].

Increased temporal resolution will be achieved by an interagency virtual scatterometer constellation. Concrete plans exist in India, China, and Russia to launch scatterometers in complementary orbit planes, thus covering several times a day, potentially increasing the deterministic NWP model resolution over sea and aiding temporal analysis in LSM [89].

The scatterometer sampling is quite uniform and the geophysical processing allows processing on user-defined grids. This could in principle prevent interpolation errors when transforming L2 to L3 or L4 products.

Finally, scatterometer products are useful in combination with other geophysical observations and aid synthesis in different application areas, as outlined in this paper. The most obvious synergy of SCA is with MWI and scientific benefits for SCA applications concern both convection (see Section VI-B) and extreme wind speeds (see Section VI-H), but note that the coarse resolution of MWI could limit usefulness. Other areas of synergy are land applications (soil moisture and vegetation) and sea ice.

The scatterometer wind processors are publicly available through the EUMETSAT NWP satellite application facility and may be extended to allow their use in open cloud computation and data infrastructures. First steps into this direction are also taken by the Earth Observation Data Centre [90], where ASCAT data are collocated with Sentinel-1 SAR and many other microwave satellite data.

SAR data are useful for the statistical assessment of artefacts in scatterometer retrievals [91]. For example, natural phenomena that exhibit different microwave responses from their neighboring targets in a scatterometer footprint, or, man-made objects, such as ships, industrial complexes, etc., that may provide synthetic or anomalous returns, which SAR data may help to control [92], [93]. Moreover, in order to be able to quantify the benefits of SCA VH cross- and HH copolarization within the sea ice and land application areas, a preliminary investigation based on SAR data is worthwhile. Also, for low VH signal exploitation, the Faraday rotation in the ionosphere must be considered.

\section{SUMMARY AND CONCLUSION}

The three major SCA innovations with respect to ASCAT are as follows.

1) Cross polarization and horizontal copolarization.

2) A nominal spatial resolution of $25 \mathrm{~km}$.

3) $20 \%$ increased spatial coverage beyond ASCAT.

This lead to substantial science and application benefits with respect to the ocean, land, and sea ice domains. Moreover, the 
novel option to implement an ocean Doppler capability to retrieve the ocean motion vector on the ocean eddy scale may be invaluable.

SCA's projected progress in extreme wind observation, soil moisture, vegetation and precipitation analyses, near-coastal processing, refined spatial and temporal analyses, sea ice extent and drift monitoring, and air-sea interaction processes is expected to benefit a wide range of applications. These include regional and global NWP, wave and storm surge forecasting, nowcasting, wind energy, hydrology, climate research and monitoring, and oceanography. This paper provides a broad overview of the anticipated scientific developments that will expectedly lead to such broad progress in the 2020-2040 time frame.

Following the above-noted enhancements offered by the SCA instrument, the associated progress in scatterometer applications is furthermore elaborated here. As such, ancillary measures of enhanced wind variability (MLE and SE) may be further exploited in scatterometer applications, such as nowcasting and NWP. Further research on the dynamical aspects of moist convection and the related physical cloud parameterizations, air-sea interaction, and ocean forcing will become more prominent as forecasting models will be increasingly coupled and enhanced in spatial resolution. Moreover, tandem scatterometers, such as ASCAT-A and ASCAT-B, will shed further light on these fast mesoscale processes.

The temporal requirement for capturing fast mesoscale and LSM processes will be further delivered through an international scatterometer constellation, supported by microwave radiometers, such as MWI. We note that the geophysical interpretation [94] and representation and/or calibration of many of these supporting sensors are expected to be inferior to SCA. Given the excellent radiometric stability of ASCAT and its further improvement in SCA, we are led to believe that SCA will be the benchmark wind and soil moisture sensor and be an excellent reference for sea ice applications.

A main driver for improvements to the global observing system, such as for SCA, is an increasing need for information on the $10-\mathrm{km}$ scale, as global and regional earth system models move to ever higher horizontal resolutions. A main challenge in the SCA era remains the exploitation of high-resolution dynamic scatterometer observations in producing deterministic weather analyses. Moreover, LSMs and sea ice models may, in the future, allow the assimilation of multiangle and/or resolution-enhanced backscatter products.

In conclusion, the SCA instrument innovations are well set to provide timely benefits in all the main application areas of the scatterometer, which in turn are generally expected to further develop to provide more sophisticated meteorological, oceanographic, hydrological, and climate services in the SCA era. SCA is further expected to continue the stable long-term reference that ASCAT provides.

\section{ACKNOWLEDGMENT}

The authors would like to thank ESA and EUMETSAT for supporting the Scatterometer Science Advisory Group, in which they participated and build SCA in collaboration with an industrial team. A great complement of in situ, satellite, and model data has been used to support the conclusions in this paper; in particular, ESA ERS and ENVISAT, EUMETAT ASCAT, RadarSat, and data from NOAA hurricane campaigns were critical in developing SCA and much appreciated. They would also like to thank all colleagues in scatterometry for their support.

\section{REFERENCES}

[1] A. Stoffelen, J. A. Verspeek, J. Vogelzang, and A. Verhoef, "The CMOD7 geophysical model function for ASCAT and ERS wind retrievals," IEEE J. Sel. Topics Appl. Earth Obs. Remote Sens., vol. 10, no. 5, pt. 2, 2017, doi: 10.1109/JSTARS.2017.2681806.

[2] J. De Kloe, A. Stoffelen, and A. Verhoef, "Improved use of scatterometer measurements by using stress-equivalent reference winds," IEEE J. Sel. Topics Appl. Earth Obs. Remote Sens., vol. 10, no. 5, pt. 2, 2017, doi: 10.1109/JSTARS.2017.2685242.

[3] G. De Chiara, M. Bonavita, and S. J. English, "Improving the assimilation of scatterometer wind observations in global NWP," vol. 10, no. 5, pt. 2, 2017. doi:2691011.

[4] G.-J. Marseille and A. Stoffelen, "Toward scatterometer winds assimilation in the mesoscale HARMONIE model," IEEE J. Sel. Topics Appl. Earth Obs. Remote Sens., vol. 10, no. 5, pt. 2, 2017, doi: 10.1109/JSTARS.2016.2640339.

[5] T. Valkonen et al., "Assimilating advanced scatterometer winds in a highresolution limited area model over northern Europe," IEEE J. Sel. Topics Appl. Earth Obs. Remote Sens., vol. 10, no. 5, pt. 2, 2017, doi: 10.1109/JSTARS.2016.2602889.

[6] S. Caires, M. Verlaan, G.-J. Marseille, and A. Stoffelen, "North sea wave predictions using data assimilation and high-resolution input data," $J$. Waterway, Port, Coastal, Ocean Eng., to be published.

[7] ESA eSurge portal. [Online]. Available: http://www.storm-surge. info/esurge, to be published.

[8] K. A. Kelly, S. Dickinson, and M. J. McPhaden, and G. C. Johnson, "Ocean currents evident in satellite wind data," Geophys. Res. Lett., vol. 28, pp. 2469-2472, 2001, doi: 10.1029/2000GL012610.

[9] R. J. Small et al., "Air-sea interaction over ocean fronts and eddies," Dyn. Atmos. Oceans, vol. 45, pp. 274-319, 2008.

[10] P. Snoeij, E. Attema, H. Hersbach, A. Stoffelen, R. Crapolicchio, and P. Lecomte, "Uniqueness of the ERS scatterometer for nowcasting and typhoon forecasting," in Proc. 2005 IEEE Int. Geosci. Remote Sens. Symp., 2005, pp. 4792-4795.

[11] C. B. Hasager et al., "Offshore wind climatology based on synergetic use of Envisat ASAR, ASCAT and QuikSCAT," Remote Sens. Environ., vol. 156, pp. 247-263, 2015, doi: 10.1016/j.rse.2014.09.030.

[12] W. Wagner et al., "The ASCAT soil moisture product: A review of its specifications, validation results, and emerging applications," Meteorologische Zeitschrift, vol. 22, pp. 5-33, 2013.

[13] V. Naeimi et al., "ASCAT surface state flag (SSF): Extracting information on surface freeze/thaw conditions from backscatter data using an empirical threshold-analysis algorithm," IEEE Trans. Geosci. Remote Sens., vol. 50, no. 7, pp. 2566-2582, Jul. 2012.

[14] L. Brocca et al., "Applications of scatterometer soil moisture data," vol. 10, no. 5, pt. 2, 2017, doi: 10.1109/JSTARS.2017.2651140.

[15] S. C. Steele-Dunne, H. McNairn, A. Monsivais-Huertero, J. Judge, P. W. Liu, and K. Papathanassiou, "Radar remote sensing of agricultural canopies: A review," IEEE J. Sel. Topics Appl. Earth Obs. Remote Sens., vol. 10, no. 5, pt. 2, 2017, doi: 10.1109/JSTARS.2016.2639043.

[16] M. Vreugdenhil et al., "Comparison of microwave vegetation indices," vol. 10, no. 5, pt. 2, 2017, doi: 10.1109/JSTARS.2016.2618838.

[17] D. Long, "Polar applications of space-borne scatterometers," IEEE J. Sel. Topics Appl. Earth Obs. Remote Sens., vol. 10, no. 5, pt. 2, 2017, doi: 10.1109/JSTARS.2016.2629418.

[18] A. Verhoef, J. Vogelzang, J. Verspeek, and A. Stoffelen, "Long-term climatological climate data records from scatterometer winds," IEEE J. Sel. Topics Appl. Earth Obs. Remote Sens., vol. 10, no. 5, pt. 2, 2017, doi: 10.1109/JSTARS.2016.2615873.

[19] F. J. Wentz et al., "Evaluating and extending the ocean wind climate data record," IEEE J. Sel. Topics Appl. Earth Obs. Remote Sens., vol. 10, no. 5, pt. 2, 2017, doi: 10.1109/JSTARS.2016.2643641.

[20] World Meteorological Organization, "Systematic observation requirements for satellite-based data products for climate," WMO, Geneva, Switzerland, Tech. Rep. GCOS-154, 2011. 
[21] Z. Wang, Ad Stoffelen, and A. Verhoef, "Empirical determination of the SST dependence of $\mathrm{Ku}$ - and C-band NRCS measurements," vol. 10, no. 5, pt. 2, 2017, doi: 10.1109/JSTARS.2016.2600749.

[22] M. Portabella and A. Stoffelen, "A probabilistic approach for SeaWinds data assimilation," Quart. J. Roy. Meteorol. Soc., vol. 130, pp. 127-152, 2004, doi: 10.1256/qj.02.205.

[23] J. Figa-Saldana, J. J. W. Wilson, E. Attema, R. Gelsthorpe, M. R. Drinkwater, and A. Stoffelen, "The advanced scatterometer (ASCAT) on the meteorological operational (MetOp) platform: A follow-on for European wind scatterometers," Can. J. Remote Sens., vol. 28, no. 3, pp. 404-414, 2002.

[24] E. P. W. Attema, "The active microwave instrument (AMI) on-board the ERS-1 satellite," Proc. IEEE, vol. 79, no. 6, pp. 791-799, Jun. 1991.

[25] M. Belmonte-Rivas, A. Stoffelen, J. Verspeek, A. Verhoef, X. Neyt, and C. Anderson, "Cone metrics: A new tool for the intercalibration of scatterometer records," IEEE J. Sel. Topics Appl. Earth Obs. Remote Sens., vol. 10, no. 5, pt. 2, 2017, doi: 10.1109/JSTARS.2017.2647842.

[26] EUMETSAT AEG, 2008. Position Papers of User Needs. [Online]. Available: www.eumetsat.int/Home/Main/Satellites/EPS-SG/Resources/ index.htm?l=en

[27] WMO OSCAR. 2017, [Online]. Available: www.wmo-sat.info/oscar/ gapanalyses?variable $=149$, www.wmo-sat.info/oscar/instruments/view/ 467

[28] F. Ticconi et al., "Analysis of radio frequency interference in ASCAT backscatter measurements," IEEE J. Sel. Topics Appl. Earth Obs. Remote Sens., vol. 10, no. 5, pt. 2, 2017, doi: 10.1109/JSTARS.2016.2640561.

[29] C. Anderson et al., "Validation and cross-validation methods for ASCAT," IEEE J. Sel. Topics Appl. Earth Obs. Remote Sens., vol. 10, no. 5, pt. 2, 2017, doi: 10.1109/JSTARS.2016.2639784.

[30] C. C. Lin, W. Lengert, and E. Attema, "Three generations of C-band wind scatterometer systems from ERS-1/2 to MetOp/ASCAT, and MetOp second generation," IEEE J. Sel. Topics Appl. Earth Obs. Remote Sens., vol. 10, no. 5, pt. 2 , 2017, doi: 10.1109/JSTARS.2016.2618838.

[31] F. Fois, P. Hoogeboom, F. Le Chevalier, A. Stoffelen, and A. Mouche, "DopSCAT: A mission concept for simultaneous measurements of marine winds and surface currents," J. Geophys. Res., Oceans, vol. 120, no. 12, pp. 7857-7879, 2015, doi: 10.1002/2015JC011011.

[32] G. J. van Zadelhoff, A. Stoffelen, P. W. Vachon, J. Wolfe, J. Horstmann, and M. Belmonte-Rivas, "Retrieving hurricane wind speeds using crosspolarization C-band measurements," Atmos. Meas. Techn., vol. 7, pp. 473449, 2014, doi: 10.5194/amt-7-437-2014

[33] F. Fois, P. Hoogeboom, F. Le Chevalier, and A. Stoffelen, "Future ocean scatterometry, on the use of cross-polar scattering to observe very high winds," IEEE Trans. Geosci. Remote Sens., vol. 53, no. 9, pp. 5009-5020, Sep. 2015, doi: 10.1109/TGRS.2015.2416203.

[34] L. Isaksen and A. Stoffelen, "ERS-scatterometer wind data impact on ECMWF's tropical cyclone forecasts," IEEE Trans. Geosci. Remote Sens., vol. 38, no. 4, pp. 1885-1892, Jul. 2000.

[35] J. W. Sapp, S. O. Alsweiss, Z. Jelenak, P. S. Chang, S. J. Frasier, and J. Carswell, "Airborne co-polarization and cross-polarization observations of the ocean-surface NRCS at C-band," IEEE Trans. Geosci. Remote Sens., vol. 54, no. 10, pp. 5975-5992, Oct. 2016, doi: 10.1109/TGRS.2016.2578048.

[36] K. A. McColl, D. Entekhabi, and M. Piles, "Uncertainty analysis of soil moisture and vegetation indices using aquarius scatterometer observations," IEEE Trans. Geosci. Remote Sens., vol. 52, no. 7, pp. 4259-4272, Jul. 2014.

[37] S. Hahn et al., "Algorithm description, implementation and validation," TU Wien, Vienna, Austria, Tech. Rep. 3, 2015. [Online]. Available: www.eumetsat.int

[38] K. C. Partington, J. D. Flach, D. Barber, D. Isleifson, P. J. Meadows, and P. Verlaan, "Dual-polarization C-band radar observations of sea ice in the Amundsen Gulf," IEEE Trans. Geosci. Remote Sens., vol. 48, no. 6, pp. 2685-2691, Jun. 2010.

[39] M. Belmonte-Rivas and A. Stoffelen, "New Bayesian algorithm for sea ice detection with QuikSCAT," IEEE Trans. Geosci. Remote Sens., vol. 49, no. 2, pp. 1894-1901, Jun. 2011, doi: 10.1109/TGRS.2010.2101608.

[40] R. De Abreu et al., "Operational sea ice monitoring with RADARSAT-2: A glimpse into the future," in Proc. Int. Geosci. Remote Sens. Symp., 2003, pp. $1308-1310$.

[41] B. J. Burn, "On the depolarization of discrete radio sources by Faraday dispersion," Monthly Notices Roy. Astron. Soc., vol. 133, pp. 67-83, 1966, doi: $10.1093 / \mathrm{mnras} / 133.1 .67$

[42] S. C. Steele-Dunne, J. Friesen, and N. Van De Giesen, "Using diurnal variation in backscatter to detect vegetation water stress," IEEE Trans. Geosci. Remote Sens., vol. 50, no. 7, 2618-2629, Jul. 2012.
[43] S. Frolking, T. Milliman, M. Palace, D. Wisser, R. Lammers, and M. Fahnestock, "Tropical forest backscatter anomaly evident in SeaWinds scatterometer morning overpass data during 2005 drought in Amazonia," Remote Sens. Environ., vol. 115, pp. 897-907, 2011.

[44] R. Schroeder, K. C. McDonald, M. Azarderakhsh, and R. Zimmermann, "ASCAT MetOp_-A diurnal backscatter observations of recent vegetation drought patterns over the contiguous U.S.: An assessment of spatial extent and relationship with precipitation and crop yield," Remote Sens. Environ., vol. 177, pp. 153-159, 2016.

[45] M. Vreugdenhil, W. A. Dorigo, W. Wagner, R. A. M. D. Jeu, S. Hahn, and M. J. E. V. Marle, "Analyzing the vegetation parameterization in the TU-Wien ASCAT soil moisture retrieval," IEEE Trans. Geosci. Remote Sens., vol. 54, no. 6, pp. 3513-3531, Jun. 2016.

[46] C. Prigent, I. Tegen, F. Aires, B. Marticoréna, and M. Zribi, "Estimation of the aerodynamic roughness length in arid and semi-arid regions over the globe with the ERS scatterometer," J. Geophys. Res., vol. 110, no. D9, 2005, Art. no. D09205, doi: 10.1029/2004JD005370.

[47] R. Quast and W. Wagner, "Analytical solution for first-order scattering in bistatic radiative transfer interaction problems of layered media," Appl. Opt., vol. 55, pp. 5379-5386, 2016.

[48] K. Morrison, "Mapping subsurface archaeology with SAR," Archaeolog. Prospection, vol. 20, pp. 149-160, 2013.

[49] S. C. M. Brown, S. Quegan, K. Morrison, J. C. Bennett, and G. Cookmartin, "High-resolution measurements of scattering in wheat canopiesimplications for crop parameter retrieval," IEEE Trans. Geosci. Remote Sens., vol. 41, no. 7, pp. 1602-1610, Jul. 2003.

[50] Y. H. Kerr et al., "Soil moisture retrieval from space: The soil moisture and ocean salinity (SMOS) mission," IEEE Trans. Geosci. Remote Sens., vol. 39, no. 8, pp. 1729-1735, Aug. 2001.

[51] M. Brown et al., "NASA's soil moisture active passive (SMAP) mission and opportunities for applications users," Bull. Amer. Meteorolog. Soc., vol. 94, no. 8, pp. 1125-1128, 2013.

[52] K. Miyaoka et al., "Triple collocation analysis of soil moisture from Metop-A ASCAT and SMOS against JRA-55 and ERA-interim", IEEE J. Sel. Topics Appl. Earth Obs. Remote Sens., vol. 10, no. 5, pt. 2, 2017, doi: 10.1109/JSTARS.2016.2632306.

[53] M. Hornáček et al., "Potential for high resolution systematic global surface soil moisture retrieval via change detection using sentinel-1," IEEE J. Sel. Topics Appl. Earth Obs. Remote Sens., vol. 5, no. 4, pp. 1303-1311, Aug. 2012.

[54] J. Vogelzang and A. Stoffelen, "The ASCAT 6.25-km wind product," IEEE J. Sel. Topics Appl. Earth Obs. Remote Sens., vol. 10, no. 5, pt. 2, 2017, doi: 10.1109/JSTARS.2016.2623862.

[55] J. Vogelzang and A. Stoffelen, "ASCAT ultra-high resolution wind products on optimized grids," IEEE J. Sel. Topics Appl. Earth Obs. Remote Sens., vol. 10, no. 5, pt. 2, 2017, doi: 10.1109/JSTARS.2016.2623861.

[56] S. Hahn et al., "Effects on level 2 soil moisture using level $1 \mathrm{~b}$ sigma0 re-sampled with a circular top-hat window and exploration of the level $1 \mathrm{~b}$ full-resolution sigma0 product," Federated activity report EUMETSAT Hydrology SAF, TU Wien, EUMETSAT, KNMI, Version 0.9, Dec. 16, 2014.

[57] S. Aaboe and T. Lavergne, "Cooperation on assessing the impact of different sigma0 re-sampling on OSI SAF sea ice products using ASCAT data," EUMETSAT and OSI SAF Federated Activity, Version 1.1, Norwegian Meteorological Institute, Mar. 2016.

[58] A. Verhoef, M. Portabella, and A. Stoffelen, "High-resolution AS CAT scatterometer winds near the coast," IEEE Trans. Geosci. Remote Sens., vol. 50, no. 7, pp. 2481-2487, Jul. 2012, doi: 10.1109/TGRS.2011.2175001.

[59] R. D. Lindsley, "A parameterized ASCAT measurement spatial response function," IEEE Trans. Geosci. Remote Sens., vol. 54, no. 8, pp. 45704579, Aug. 2016, doi: 10.1109/TGRS.2016.2544835.

[60] S. Zwieback, A. Bartsch, T. Melzer, and W. Wagner, "Probabilistic fusion of $\mathrm{Ku}$ - and C-band scatterometer data for determining the freeze/thaw state," IEEE Trans. Geosci. Remote. Sens., vol. 50, no. 7, pp. 2583-2594, Jul. 2012.

[61] J. Verspeek and Ad Stoffelen, “ASCAT tandem coverage," EUMETSAT Ocean and Sea Ice SAF report, Version 0.8, 2009-04-22, 2009.

[62] CEOS Ocean surface vector winds-virtual constellation, 2017. [Online]. Available: ceos.org/ourwork/virtual-constellations/osvw/

[63] J. Cotton, "The impact of ASCAT winds from metop-B and a new scatterometer thinning scheme," Met Office, Exeter, U.K., Tech. Rep. 580, 2013.

[64] C. Bertrand, C. Fabrice, and A. Fabrice, "Direct measurements of ocean surface velocity from space: Interpretation and validation," $J$. 
Geophys. Res. Oceans, vol. 110, no. (C7), pp. 76-92, 2005, doi: dx.doi.org/10.1029/2004JC002809.

[65] M. J. Rouault, M. Alexis, C. Fabrice, J. A. Johannessen, and C. Bertrand, "Mapping the Agulhas current from space: An assessment of ASAR surface current velocities," J. Geophys. Res., Oceans, vol. 115, 2010, pp. 1-14. doi: dx.doi.org/10.1029/2009JC006050.

[66] M. Alexis et al., "On the use of Doppler shift for sea surface wind retrieval from SAR," IEEE Trans. Geosci. Remote Sens., vol. 50, no. 7, pp. 29012909, Jul. 2012, doi: http://dx.doi.org/10.1109/TGRS.2011.2174998.

[67] W. Lin, M. Portabella, A. Stoffelen, A. Turiel, and A. Verhoef, "Rain identification in ASCAT winds using singularity analysis," IEEE Geosci. Remote Sens. Lett., vol. 11, no. 9, pp. 1519-1523, Sep. 2014, doi: 10.1109/LGRS.2014.2298095.

[68] ESA GlobCurrent project. [Online]. Available: www.globcurrent.org/

[69] A. Stoffelen, "Scatterometry," Ph.D. dissertation, IMAU, Utrecht Univ., Utrecht, The Netherlands, 1998. [Online]. Available: dspace. library.uu.nl/handle/1874/636

[70] M. Portabella and A. Stoffelen, "Rain detection and quality control of SeaWinds," J. Atmos. Ocean. Technol., vol. 18, no. 7, pp. 1171-1183, 2001.

[71] M. Portabella et al., "Rain effects on ASCAT retrieved winds: Towards an improved quality control," IEEE Trans. Geosci. Remote Sens., vol. 50, no. 7, pp. 2495-2506, Jul. 2012.

[72] W. Lin, M. Portabella, A. Stoffelen, A. Verhoef, and A. Turiel, "ASCAT wind quality control near rain," IEEE Trans. Geosci. Remote. Sens., vol. 53 , no. 8, pp. 4165-4177, Aug. 2015.

[73] W. Lin, M. Portabella, A. Stoffelen, J. Vogelzang, and A. Verhoef, "On mesoscale analysis and ASCAT ambiguity removal," Quart. J. Roy. Meteorolog. Soc., vol. 142, pp. 1745-1756, 2016, doi: 10.1002/qj.2770.

[74] K. Morrison, J. C. Bennett, M. Nolan, and R. Menon, "Laboratory measurement of the DInSAR response to spatio-temporal variations in soil moisture," IEEE Trans. Geosci. Remote Sens., vol. 49, no. 10, pp. 38153823, Oct. 2011.

[75] P.-W. Liu, J. Judge, R. D. DeRoo, A. W. England, T. Bongiovanni, and A. Luke, "Dominant backscattering mechanisms at L-band during dynamic soil moisture conditions for sandy soils," Remote Sens. Environ., vol. 178 , pp. 104-112, 2016.

[76] M. Rodell et al., "The global land data assimilation system," Bull. Amer. Meteorolog. Soc., vol. 85, pp. 381-394, 2004.

[77] [Online]. Available: https://groups.ssec.wisc.edu/groups/iwwg/activities/ high-resolution-winds-1/nwp-data-assimilation

[78] S. Abdalla and G. DeChiara, "Estimating random errors of scatterometer, altimeter and model wind speed data," IEEE J. Sel. Topics Appl. Earth Obs. Remote Sens., vol. 10, no. 5, pt. 2, 2017, doi: 10.1109/JSTARS.2017.2659220.

[79] I. Sandu, A. Beljaars, P. Bechtold, T. Mauritsen, and G. Balsamo, "Why is it so difficult to represent stably stratified conditions in numerical weather prediction (NWP) models?" J. Adv. Model. Earth Syst., vol. 5, pp. 117133, 2011, doi: 10.1002/jame.20013.

[80] G. King, J. Vogelzang, and A. Stoffelen, "Second-order structure function analysis of scatterometer winds over the Tropical Pacific," J. Geophys. Res., vol. 120, pp. 362-383, 2015, doi: 10.1002/2014JC009992.

[81] H. M. Holbach and M. Bourassa, "Platform and across-swath comparison of vorticity spectra from QuikSCAT, ASCAT-A, OSCAT, and ASCAT-B scatterometers," IEEE J. Sel. Topics Appl. Earth Obs. Remote Sens., vol. 10, no. 5, pt. 2, 2017, doi: 10.1109/JSTARS.2016.2642583.

[82] P. Laloyaux, M. Balmaseda, D. Dee, K. Mogensen, and P. Janssen, "A coupled data assimilation system for climate reanalysis," Quart. J. Roy. Meteorolog. Soc., vol. 142, pp. 65-78, 2016, doi: 10.1002/qj.2629.

[83] D. J. Lea et al., "Assessing a new coupled data assimilation system based on the met office coupled atmosphere-land-ocean-sea ice model," Monthly Weather Rev., vol. 143, pp. 4678-4694, 2015, doi: 10.1175/MWR-D-15-0174.1.

[84] S. Saha et al. "The NCEP climate forecast system reanalysis," Bull. Amer. Meteorolog. Soc., vol. 91, pp. 1015-1057, 2010, doi: 10.1175/2010BAMS3001.1

[85] M. Belmonte-Rivas, A. Stoffelen, and G. J. van Zadelhoff, "The benefit of $\mathrm{HH}$ and $\mathrm{VV}$ polarizations in retrieving extreme wind speeds for an ASCAT-type scatterometer," IEEE Geosci. Remote Sens. Lett., vol. 52, no. 7, 4273-4280, Jul. 2014, doi: 10.1109/TGRS.2013.2280876.

[86] G. De Chiara et al., "Status of scatterometer winds in the ECMWF system: Operational and research activities," in Proc. 2015 EUMETSAT Meteorolog. Satellite Conf., Toulouse, France, Sep. 2015.

[87] D. G. Long et al., "Comparison of SeaWinds backscatter imaging algorithms," IEEE J. Sel. Topics Appl. Earth Obs. Remote Sens., vol. 10, no. 5, pt. 2, 2017, doi: 10.1109/JSTARS.2016.2626966.
[88] L. Liu et al., "Spatial resolution and precision properties of scatterometer reconstruction algorithms," IEEE J. Sel. Topics Appl. Earth Obs. Remote Sens., vol. 10, no. 5, pt. 2, 2017, doi: 10.1109/JSTARS.2016.2646840.

[89] S. Hahn, et al. "Dynamic characterization of the incidence angle dependence of backscatter using metop ASCAT," IEEE J. Sel. Topics Appl. Earth Obs. Remote Sens., vol. 10, no. 5, pt. 2, 2017, doi: 10.1109/JSTARS.2016.2628523.

[90] W. Wagner et al., "Addressing grand challenges in earth observation science: The earth observation data centre for water resources monitoring," in Proc. 2014 ISPRS Techn. Commission VII Mid-Term Symp., Istanbul, Turkey, 2014, pp. 81-88.

[91] J. E. Stopa et al., "Sea state impacts on wind speed retrievals from C-band radars," IEEE J. Sel. Topics Appl. Earth Obs. Remote Sens., vol. 10, no. 5, pt. 2, 2017, doi: 10.1109/JSTARS.2016.2609101.

[92] A. Ferro, D. Brunner, L. Bruzzone, and G. Lemoine, "On the relationship between double bounce and the orientation of buildings in VHR SAR images," IEEE Geosci. Remote Sens. Lett., vol. 8, no. 4, pp. 612-616, Jul. 2011

[93] S. Auer and S. Gernhardt, "Linear signatures in urban SAR imagesPartly misinterpreted?" IEEE Geosci. Remote Sens. Lett., vol. 11, no. 10, pp. 1762-1766, Oct. 2014.

[94] W. Lin et al., "Towards an improved wind inversion algorithm for RapidScat," IEEE J. Sel. Topics Appl. Earth Obs. Remote Sens., vol. 10, no. 5, pt. 2, 2017, doi: 10.1109/JSTARS.2016.2616889.

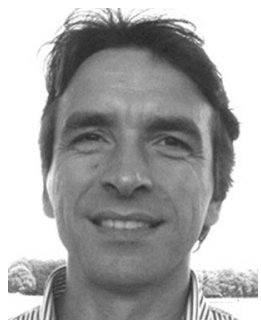

Ad Stoffelen (M'13-SM'14) received the M.Sc. degree in physics from the Technical University of Eindhoven, Eindhoven, The Netherlands, in 1987, and the $\mathrm{Ph}$.D. degree in meteorology on scatterometry from the University of Utrecht, Utrecht, The Netherlands, in 1998.

He currently leads a group on active satellite sensing with Royal Netherlands Meteorology Institute, De Bilt, The Netherlands, and is involved in topics ranging from future missions and $R \& D$ for retrieval to $24 / 7$ operations, user training, and services. Establishing an international scatterometer virtual constellation is one of his main aims. He is also deeply involved in the ESA ADM-Aeolus Doppler Wind LIDAR mission.

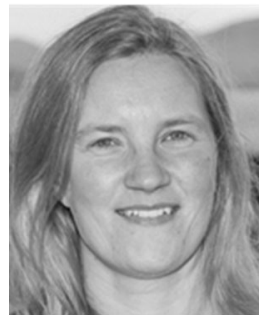

Signe Aaboe received the M.Sc. degree in physics geophysics from the University of Copenhagen, Copenhagen, Denmark, in 2003, and the Ph.D. degree in physical oceanography from the University of Bergen, Bergen, Norway, in 2008.

From 2008 to 2011, she was with Norwegian Polar Institute on polar oceanography. From 2012 to 2015, she was with the Arctic University of Norway, University of Tromsoe, as an Associate Professor II in physical oceanography. Since 2013, she has been a Sea Ice Remote Sensing Scientist in the Department of Sea and Ice, Norwegian Meteorological Institute, Tromso, Norway.

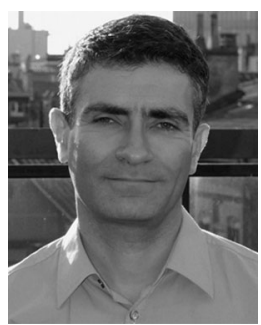

Jean-Christophe Calvet received the M.Eng. degree in agronomy from AgroParisTech, Paris, France, in 1990, the M.Sc./Eng. degree in meteorology from the Ecole Nationale de la Météorologie, Toulouse, France, in 1990, the Ph.D. degree from the Universite Paul Sabatier, Toulouse, in 1996, and the Habilitation degree in 2002 at the same university.

He joined Météo-France, Toulouse, the French meteorological service, in 1990, and Centre National de la Recherches Météorologiques, Toulouse, in 1994, where he has been the Head of a land modeling and remote sensing section since 2003. His most recent works concern the joint analysis of soil moisture and vegetation biomass, and the representation of the carbon cycle in climate models. His research interests include land-atmosphere exchange modeling and the use of remote sensing over land surfaces for meteorology.

James Cotton received the B.Sc. (Hons.) degree in mathematics from the University of Exeter, Exeter, U.K, in 2008.

After graduating, he joined the satellite applications section with the Met Office, Exeter, to work on the assimilation of satellite-derived wind observations in to numerical weather prediction models. 
Giovanna De Chiara received the Graduate degree in marine environmental sciences, curriculum in oceanography, from the "Parthenope" University of Naples, Napoli, Italy, in 2002, and the Ph.D. degree in civil and environmental engineering from the University of Salerno, Fisciano, Italy, in 2010.

From 2003 to 2005, she was with the Institute of Biometeorology, Italy, where she collaborated on different projects regarding meteorological hazards and climate change. In 2006, she received the grant from the National Research Institute Consorzio Inter-Universitario per la Previsione e Prevenzione dei Grandi RIschi, where she worked on remote sensing techniques for meteorological and flood risk analysis. From 2007 to 2010, she was with Serco S.p.A., Frascati, Italy, as a Remote Sensing Engineer responsible for the quality control of ERS-2 scatterometer data. Since 2011, she has been with European Centre for Medium-Range Weather Forecasts, Reading, U.K., on the validation and assimilation of wind scatterometer data.

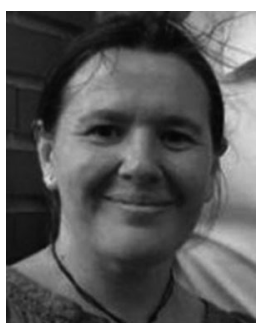

Julia Figa Saldaña received the M.Sc. degree in civil engineering from the Universitat Politecnica de Catalunya, Barcelona, Spain, in 1993.

Since 1993, she has been involved in radar remote sensing processing and applications. She joined Europäische Organisation für meteorologische Satelliten (EUMETSAT), Darmstadt, Germany, in 1999 and was involved in the specification and development of the advanced scaterometer mission processing and cal/val activities, later going on to support the EUMETSAT Polar System Operations. From 2013, she led the science and operational support to activities related to marine meteorology applications, particularly for the EUMETSAT scatterometer programs and cochairing the ESA/EUMETSAT Scatterometer Science Advisory Group. In June 2016, she joined the Jason-CS/Sentinel-6 Project at EUMETSAT as a Ground Segment Manager.

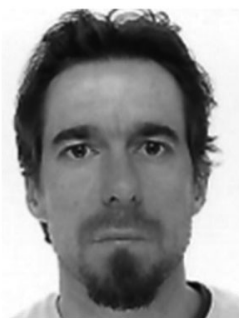

Alexis Aurélien Mouche received the Ph.D. degree in ocean remote sensing in 2005 at the Université de Versailles Saint-Quentin, France.

$\mathrm{He}$ has a permanent position with the Laboratoire d'Océanographie Physique et Spatiale, Institut Français de Recherche pour l'Exploitation de la Mer, Plouzane, France, since January 2014. His principal field of interest is the interaction of electromagnetic and oceanic waves for ocean remote sensing applications.

Dr. Mouche is a member of the EUMETSAT/ESA

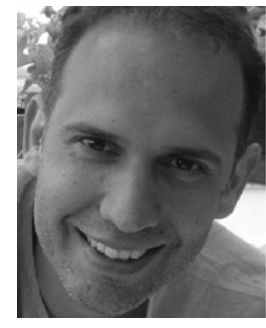

Marcos Portabella was born in Spain, on October 14, 1970. He received the B.Sc. degree in physics from the University of Barcelona, Barcelona, Spain, in 1994; the M.Sc. degree in remote sensing from the Institute of Space Studies of Catalonia, Barcelona, in 1995; and the Ph.D. degree in physics from the University of Barcelona in 2002.

$\mathrm{He}$ is currently with the Institut de Ciències de Mar-Spanish National Research Council, Barcelona, working on satellite remote sensing. In particular, he is involved in scatterometry and L-band radiometry

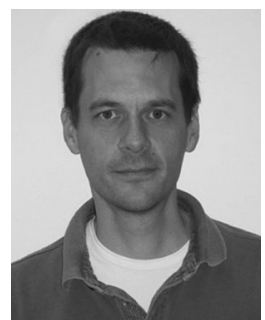

Klaus Scipal received the M.Sc. degree in geodesy and the Ph.D. degree in remote sensing from Vienna University of Technology (VUT), Vienna, Austria, in 1999 and 2002 respectively.

From 2002 to 2006, he was an Assistant Professor with VUT leading the scatterometer applications team. In 2006, he joined the satellite data assimilation section of the European Centre for Medium Range Weather Forecasts, working on the land surface assimilation system. Since 2009, he has been with European Space Agency, Noordwijk, The Netherlands, where he is a Mission Scientist for the Earth Explorer Biomass and Metop-SG SCA missions.

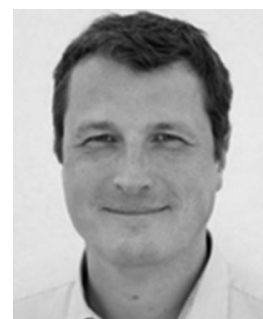

Wolfgang Wagner (M'98-SM'07) received the M.Sc. degree in physics and the Ph.D. degree in remote sensing from Vienna University of Technology (TU Wien), Vienna, Austria, in 1995 and 1999, respectively.

He received fellowships to carry out research with the University of Bern, AES Canada, NASA, ESA, and the EC JRC. From 1999 to 2001, he was with DLR. In 2001, he was appointed the Professor in remote sensing with TU Wien. Since 2012, he has been the Head in the Department of Geodesy and Geoinformation, TU Wien. He is the Cofounder and Head of science of the Earth Observation Data Centre. His main research focuses on physical interaction of electromagnetic waves with the land surface and models for retrieving soil moisture, biomass, and other land surface variables from scatterometer, SAR, and full-waveform LIDAR observations.

Dr. Wagner is a Member of the EUMETSAT/ESA SCA SAG, and since 2016 chair of the GCOS/WCRP Terrestrial Observation Panel for Climate. From 2008 to 2012 he served as ISPRS Commission VII President and from 2009-2011 as editor-in-chief of the Open Access Journal "Remote Sensing". He is a recipient of the ISPRS Frederick J. Doyle Award for his scientific contributions in active remote sensing.

SCA SAG. 